\title{
Internet-based cognitive behavioral therapy realizes long- term improvement in the sexual functioning and body image of breast cancer survivors
}

Citation for published version (APA):

Hummel, S. B., van Lankveld, J. J. D. M., Oldenburg, H. S. A., Hahn, D. E. E., Kieffer, J. M., Gerritsma, M. A., Kuenen, M. A., Bijker, N., Borgstein, P. J., Heuff, G., Cardozo, A. M. F. L., Plaisier, P. W., Rijna, H., van der Meij, S., van Dulken, E. J., Vrouenraets, B. C., Broomans, E., \& Aaronson, N. K. (2018). Internet-based cognitive behavioral therapy realizes long-term improvement in the sexual functioning and body image of breast cancer survivors. Journal of Sex \& Marital Therapy, 44(5), 485-496.

https://doi.org/10.1080/0092623X.2017.1408047

DOI:

10.1080/0092623X.2017.1408047

Document status and date:

Published: 01/01/2018

Document Version:

Publisher's PDF, also known as Version of record

Please check the document version of this publication:

- A submitted manuscript is the version of the article upon submission and before peer-review. There can be important differences between the submitted version and the official published version of record. People interested in the research are advised to contact the author for the final version of the publication, or visit the DOI to the publisher's website.

- The final author version and the galley proof are versions of the publication after peer review.

- The final published version features the final layout of the paper including the volume, issue and page numbers.

Link to publication

\section{General rights}

Copyright and moral rights for the publications made accessible in the public portal are retained by the authors and/or other copyright owners and it is a condition of accessing publications that users recognise and abide by the legal requirements associated with these rights.

- Users may download and print one copy of any publication from the public portal for the purpose of private study or research.

- You may not further distribute the material or use it for any profit-making activity or commercial gain

- You may freely distribute the URL identifying the publication in the public portal.

If the publication is distributed under the terms of Article 25fa of the Dutch Copyright Act, indicated by the "Taverne" license above, please follow below link for the End User Agreement:

https://www.ou.nl/taverne-agreement

Take down policy

If you believe that this document breaches copyright please contact us at:

pure-support@ou.nl

providing details and we will investigate your claim.

Downloaded from https://research.ou.nl/ on date: 26 Apr. 2023 


\section{Internet-Based Cognitive Behavioral Therapy Realizes Long-Term Improvement in the Sexual Functioning and Body Image of Breast Cancer Survivors}

Susanna B. Hummel, Jacques J. D. M. van Lankveld, Hester S. A. Oldenburg, Daniela E. E. Hahn, Jacobien M. Kieffer, Miranda A. Gerritsma, Marianne A. Kuenen, Nina Bijker, Paul J. Borgstein, Gijsbert Heuff, Alexander M. F. Lopes Cardozo, Peter W. Plaisier, Herman Rijna, Suzan van der Meij, Eric J. van Dulken, Bart C. Vrouenraets, Eva Broomans \& Neil K. Aaronson

To cite this article: Susanna B. Hummel, Jacques J. D. M. van Lankveld, Hester S. A. Oldenburg, Daniela E. E. Hahn, Jacobien M. Kieffer, Miranda A. Gerritsma, Marianne A. Kuenen, Nina Bijker, Paul J. Borgstein, Gijsbert Heuff, Alexander M. F. Lopes Cardozo, Peter W. Plaisier, Herman Rijna, Suzan van der Meij, Eric J. van Dulken, Bart C. Vrouenraets, Eva Broomans \& Neil K. Aaronson (2018) Internet-Based Cognitive Behavioral Therapy Realizes Long-Term Improvement in the Sexual Functioning and Body Image of Breast Cancer Survivors, Journal of Sex \& Marital Therapy, 44:5, 485-496, DOI: 10.1080/0092623X.2017.1408047

To link to this article: https://doi.org/10.1080/0092623X.2017.1408047

Accepted author version posted online: 03 Jan 2018. Published online: 15 Feb 2018.

山ll Article views: 120

View Crossmark data ¿ 


\title{
Internet-Based Cognitive Behavioral Therapy Realizes Long-Term Improvement in the Sexual Functioning and Body Image of Breast Cancer Survivors
}

Susanna B. Hummel ${ }^{a}$, Jacques J. D. M. van Lankveld ${ }^{b}$, Hester S. A. Oldenburg ${ }^{c}$, Daniela E. E. Hahnd,e , Jacobien M. Kieffer ${ }^{a}$, Miranda A. Gerritsma ${ }^{a}$, Marianne A. Kuenen ${ }^{a}$, Nina Bijker ${ }^{f}$, Paul J. Borgstein ${ }^{g}$, Gijsbert Heuff ${ }^{h}$, Alexander M. F. Lopes Cardozo', Peter W. Plaisier ${ }^{j}$, Herman Rijna ${ }^{k}$, Suzan van der Meij', Eric J. van Dulken ${ }^{m}$, Bart C. Vrouenraets ${ }^{n}$, Eva Broomans ${ }^{o, p}$, and Neil K. Aaronson ${ }^{a}$

\begin{abstract}
${ }^{a}$ Division of Psychosocial Research and Epidemiology, The Netherlands Cancer Institute, Amsterdam, The Netherlands; ${ }^{b}$ Faculty of Psychology and Educational Sciences, Open University of The Netherlands, Heerlen, The Netherlands; 'Department of Surgical Oncology, The Netherlands Cancer Institute, Amsterdam, The Netherlands; ${ }^{\mathrm{d}}$ Department of Psychosocial Counseling, The Netherlands Cancer Institute, Amsterdam, The Netherlands; ${ }^{\mathrm{e} F a m i l y}$ Cancer Clinic, The Netherlands Cancer Institute, Amsterdam, The Netherlands; ${ }^{f}$ Department of Radiotherapy, Academic Medical Center, Amsterdam, The Netherlands; ${ }^{9}$ Department of Surgical Oncology, Onze Lieve Vrouwe Gasthuis Location East, Amsterdam, The Netherlands; ${ }^{\text {h }}$ Department of Surgical Oncology, Spaarne Gasthuis Hoofddorp, Hoofddorp, The

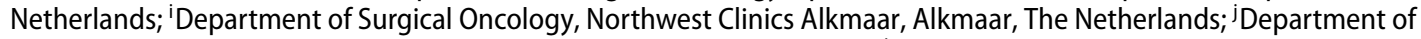

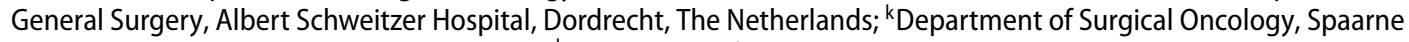
Gasthuis Haarlem, Haarlem, The Netherlands; 'Department of Surgical Oncology, Flevo Hospital, Almere, The Netherlands; ${ }^{\mathrm{m}}$ Department of Surgical Oncology, Medical Center Slotervaart, Amsterdam, The Netherlands; ${ }^{n}$ Department of Surgery, Onze Lieve Vrouwe Gasthuis Location West, Amsterdam, The Netherlands; ${ }^{\circ}$ Department of Adult Care, Virenze Institute of Mental Health Care, Utrecht, The Netherlands; ${ }^{\mathrm{P} P s y Q}$ Institute of Mental Health Care, Almere, The Netherlands
\end{abstract}

\begin{abstract}
The study aim was to evaluate the long-term efficacy of Internet-based cognitive behavioral therapy (CBT) for sexual dysfunctions in 84 breast cancer survivors. The positive effects of the intervention on overall sexual functioning, sexual desire, sexual arousal, vaginal lubrication, discomfort during sex, sexual distress, and body image observed immediately posttreatment were maintained at three- and nine-month follow-ups. Although sexual pleasure decreased during follow-up, it did not return to baseline levels. Our findings provide evidence that Internet-based CBT has a sustained, positive effect on sexual functioning and body image of breast cancer survivors with a sexual dysfunction.
\end{abstract}

\section{Introduction}

Sexual problems are common among women who have been treated for breast cancer (BC) (Kedde, van de Wiel, Weijmar Schultz, \& Wijsen, 2013; Raggio, Butryn, Arigo, Mikorski, \& Palmer, 2014; Sadovsky et al., 2010), with prevalence rates of $45 \%$ to $77 \%$ (Kedde et al., 2013; Raggio et al., 2014). The standard treatment for female sexual dysfunction is cognitive behavioral therapy (CBT) (Ter Kuile, Both, \& van Lankveld, 2010), which is traditionally delivered in a face-to-face setting. More recently, Internet-based sex therapy for both men and women has been shown to be effective (Hucker \& McCabe, 2014; Jones

CONTACT Neil K. Aaronson n.aaronson@nki.nl The Netherlands Cancer Institute, Division of Psychosocial Research and Epidemiology, Plesmanlaan 121, 1066 CX Amsterdam, The Netherlands. 
\& McCabe, 2011; Van Lankveld, Leusink, Van Diest, Gijs, \& Slob, 2009). First trials have demonstrated the efficacy of Internet-based CBT (Jones \& McCabe, 2011) and an online mindfulness-based CBT (Hucker \& McCabe, 2014) for female sexual dysfunction in the general population. Schover et al. (2013) demonstrated the feasibility of a 12-week Internet-based self-help intervention for sexual problems specifically in BC and gynecological cancer survivors. We previously reported on the short-term (i.e., immediate postintervention) results of a randomized controlled trial (RCT) of the efficacy of an Internet-based CBT in improving the sexual functioning of BC survivors (Hummel et al., 2017). Women who underwent the intervention reported significantly greater improvement in overall sexual functioning, sexual desire, sexual arousal, vaginal lubrication, sexual pleasure, discomfort during sex, sexual distress, and body image from baseline to immediate post-CBT assessment, as compared to women in a waiting-list control group. No significant group differences from baseline to immediate post-CBT were observed for orgasmic function, sexual satisfaction, sexual pain, intercourse frequency, relationship intimacy, menopausal symptoms, marital functioning, psychological distress, or health-related quality of life.

In the current article, we report the results of the longer-term evaluation of the intervention effects as assessed at three and nine months post-CBT. Our interest was in determining if the positive treatment effects observed in the short term were sustained over time, and whether there were additional longerterm benefits of treatment that emerged only during the longer follow-up period.

\section{Method}

\section{Participants}

From September 2013 to May 2015, we recruited women with a history of BC and a diagnosis of sexual dysfunction from 10 hospitals in the Netherlands. Inclusion criteria were as follows: age 18 to 65 years; a diagnosis of histologically confirmed $\mathrm{BC}$ six months to five years prior to study entry; completion of BC treatment (with the exception of maintenance endocrine therapy and immunotherapy); disease-free at time of study entry; sufficient command of the Dutch language; and a sexual dysfunction diagnosed by a psychologist/sexologist during a diagnostic interview using the criteria of the Diagnostic and Statistical Manual of Mental Disorders (4th ed., text rev.; DSM-IV-TR; American Psychiatric Association, 2000). Single as well as partnered women could participate. Sexual orientation was irrelevant for eligibility.

Exclusion criteria were as follows: no Internet access; serious psychiatric comorbidity (e.g., depressive disorder, alcohol dependency), as these problems often need to be treated first before addressing a sexual dysfunction (Brotto et al., 2016); treatment for another type of cancer (with the exception of cervix carcinoma in situ and basal cell carcinoma); presence of severe relationship problems; concurrent therapy to alleviate problems with sexuality/intimacy; concurrent CBT for other psychological problems; and participation in another trial investigating problems with sexuality/intimacy. The institutional review boards of all recruiting hospitals approved the trial.

\section{Procedure}

We identified potentially eligible patients (i.e., those who met criteria in terms of age, BC diagnosis, time since diagnosis and current disease status) via hospital databases and/or the Netherlands Cancer Registry. Patients received a letter describing the study and were asked to return a postcard indicating if they were potentially interested in participating. Interested women were interviewed by phone by a member of the study staff to confirm basic eligibility for the trial. Subsequently, women were interviewed by phone by a psychologist/sexologist to determine if they met $D S M-I V-T R$ criteria for one or more diagnoses of sexual dysfunction. Women who were eligible for and interested in trial participation were sent a baseline questionnaire and an informed consent form. Consenting women were randomly assigned to either a waiting-list control group or a group undergoing the Internet-based CBT. 


\section{Internet-based CBT}

Extensive information on the content of the Internet-based CBT is provided elsewhere (Hummel et al., 2017). Briefly, the CBT was composed of four to five modules (selected out of a total of 10 modules by the psychologist/sexologist) that best suited the sexual problems of each individual participant. Each module included information texts on a range of topics, including the nature of sexual problems, the biopsychosocial model, the sexual response curve, the interplay between sexuality and intimacy, and communication with the partner. Accompanying homework exercises included sensate focus exercises, task concentration training, exposure exercises for sexual pain, and cognitive restructuring. This resulted in a therapy of approximately 20 therapist-guided weekly sessions to be completed within 24 weeks. The contact between the therapist and participant took place via email, with the addition of two telephone contacts, one at mid-CBT and one at completion of the CBT.

\section{Timing of Assessments}

Study questionnaires were completed at baseline (T0), mid-CBT (T1), post-CBT (T2), and at three(T3) and nine-month (T4) follow-ups. The results of the RCT pertaining to the effects of the Internetbased CBT from T0 to T2 have been reported in detail previously (Hummel et al., 2017). The T3 and T4 assessments were completed by the intervention group only, as women in the waiting-list control group were offered the opportunity to undergo the Internet-based CBT immediately after completion of the T2 assessment and thus did not complete the follow-up assessments.

\section{Study Measures}

Sociodemographic and basic clinical information was obtained during screening and via the baseline questionnaire. We assessed the primary outcomes, sexual functioning and relationship intimacy, at all five assessment points. Sexual functioning was measured with the Female Sexual Function Index (FSFI;Rosen et al., 2000; Ter Kuile, Brauer, \& Laan, 2006), the Sexual Activity Questionnaire (SAQ; Atkins \& Fallowfield, 2007; Thirlaway, Fallowfield, \& Cuzick, 1996), and the Female Sexual Distress ScaleRevised (FSDS-R; Derogatis, Clayton, Lewis-D’Agostino, Wunderlich, \& Fu, 2008; Derogatis, Rosen, Leiblum, Burnett, \& Heiman, 2002). Relationship intimacy was measured with the Personal Assessment of Intimacy in Relationships Inventory (PAIR; Schaefer \& Olson, 1981).

At T0 through T3, we assessed the following secondary outcomes: body image (subscale of the European Organisation for Research and Treatment of Cancer breast cancer module [QLQ-BR23]; Sprangers et al., 1996), menopausal symptoms (Functional Assessment of Cancer Treatment-Endocrine Symptoms [FACT-ES]; Fallowfield, Leaity, Howell, Benson, \& Cella, 1999), marital functioning (Maudsley Marital Questionnaire [MMQ]; Arrindell, Boelens, \& Lambert, 1983), psychological distress (Hospital Anxiety and Depression Scale [HADS]; Bjelland, Dahl, Haug, \& Neckelmann, 2002; Zigmond \& Snaith, 1983), and health-related quality of life (36-item Short Form Health Survey [SF-36]; Aaronson et al., 1998; Ware \& Sherbourne, 1992). A more detailed description of all outcome measures is provided elsewhere (Hummel et al., 2017).

\section{Statistical Analysis}

We calculated questionnaire scores according to published scoring algorithms. Missing values were replaced by the average score of the completed items in the same scale for each individual, provided that $\geq 50 \%$ of the items in that scale had been completed.

To evaluate the intra-individual difference in the trajectory of change over time for both the primary and secondary outcomes, we used a growth curve modeling approach based on restricted maximum likelihood estimation with random intercept and slope. We checked for the presence of a linear effect of time from T0 to T3 or T4. Subsequently, we added a quadratic effect of time to the model to determine if an initial improvement or deterioration in the outcome was followed by a deceleration of this change 
over time. The choice between the model including only a linear effect of time and the model including both a linear and quadratic effect of time was based on model fit statistics: the Bayesian information criterion (BIC; Schwarz, 1978) and the Akaike information criterion (AIC; Akaike, 1998).

If, for a primary outcome, the model including a quadratic effect of time had the best fit and was statistically significant, we fitted a piecewise linear growth model to the data (Hernández-Lloreda, Colmenares, \& Martínez-Arias, 2004). Piecewise linear growth models can be used when specific transition points can be specified, such as the end of treatment. They model nonlinearity by including two interrelated linear slopes reflecting the growth trajectory before and after this transition point (Bollen \& Curran, 2006). In our analyses the transition point was the end of CBT, with an active treatment phase before (P1: pre-, mid-, and immediate posttreatment) and the follow-up phase after this transition point (P2: immediate posttreatment, three-month, and nine-month follow-up) (Hernández-Lloreda et al., 2004). We tested if changes during the active treatment and follow-up period were significantly different from zero. Evidence of a sustained effect of the Internet-based CBT over time was considered present if, after a statistically significant improvement in the outcome during P1, the time coefficient for P2 was nonsignificant. The change during the active treatment phase and follow-up period was accompanied by effect sizes, and was based on the $t$-test statistic: $\left(2^{*} t\right) /(\sqrt{ } d f)$. An effect size of .20 was considered small, .50 moderate and clinically significant, and .80 large (Cohen, 1988).

As the secondary outcomes were not assessed at T4 (see the Discussion section), we decided not to use a piecewise growth model on these outcomes, as too few measurement points were available. Instead, we evaluated the presence of a linear and quadratic effect of time and subsequently calculated effect sizes based on the mean scores and pooled standard deviation (see Tables 1 and 2). The $p$ value for statistical significance was set at .05. All analyses were conducted on an intention-to-treat basis.

\section{Results}

Recruitment and participant flow in the trial is reported in detail elsewhere (Hummel et al., 2017). Specific to the current analysis, 169 women were randomly assigned into the trial, with 84 assigned to the intervention group. All 84 women completed the T0 questionnaire, 75 (89.3\%) completed the T1 assessment, $69(82.1 \%)$ the T2 assessment, $64(76.2 \%)$ the T3 assessment, and $65(77.4 \%)$ the T4 assessment.

The mean age of the intervention group was 51.6 years $(S D=7.7)$, most had completed post-high school education (76.2\%), were employed (77.4\%), and the large majority had a partner (97.6\%). The majority was postmenopausal $(84.5 \%)$ and sexually active at baseline $(73.8 \%)$. The mean time since $\mathrm{BC}$ diagnosis was 38.1 months $(S D=17.0)$. The majority had undergone breast-conserving treatment (58.3\%), followed by a mastectomy with reconstruction (22.6\%), and a mastectomy only (19.0\%). The majority had undergone chemotherapy (77.4\%), endocrine therapy (84.5\%), and radiotherapy (86.9\%). Twenty percent of the women had undergone immunotherapy.

The majority of women (57.1\%) were diagnosed with two sexual dysfunctions according to DSM-IVTR criteria (versus $32.1 \%$ with one dysfunction, and $10.7 \%$ with three dysfunctions), the most prevalent of which was hypoactive sexual desire disorder (82.1\%), followed by sexual arousal disorder (42.9\%), dyspareunia (32.1\%), orgasmic disorder (9.5\%), sexual aversion disorder (6.0\%), sexual dysfunction not otherwise specified (4.8\%), and vaginismus (1.2\%). The majority of women (67.9\%) first experienced sexual problems during the $\mathrm{BC}$ treatment (versus $11.9 \%$ before and $20.2 \%$ after $\mathrm{BC}$ treatment).

At both T3 and T4, 7.7\% of women reported using antidepressants. At T3 and T4, 4.6\% and 9.4\% reported using sedatives, and $9.2 \%$ and $6.3 \%$ reported using sleep medications, respectively. Only one woman reported having had contact with a psychologist for her sexual dysfunction after completion of the CBT program.

The CBT was completed successfully (according to the judgment of the therapist) by $61.9 \%$ of the women, $31.0 \%$ ended the CBT prematurely, and $7.1 \%$ never started the CBT. The most common reasons for ending the CBT prematurely were personal circumstances (15.2\%), time constraints $(12.1 \%)$, the intensity of the CBT (9.1\%), relationship problems (9.1\%), or dislike of the online approach $(9.1 \%)$. The reasons for women not starting the CBT (after agreeing to do so) were time constraints (two women), 


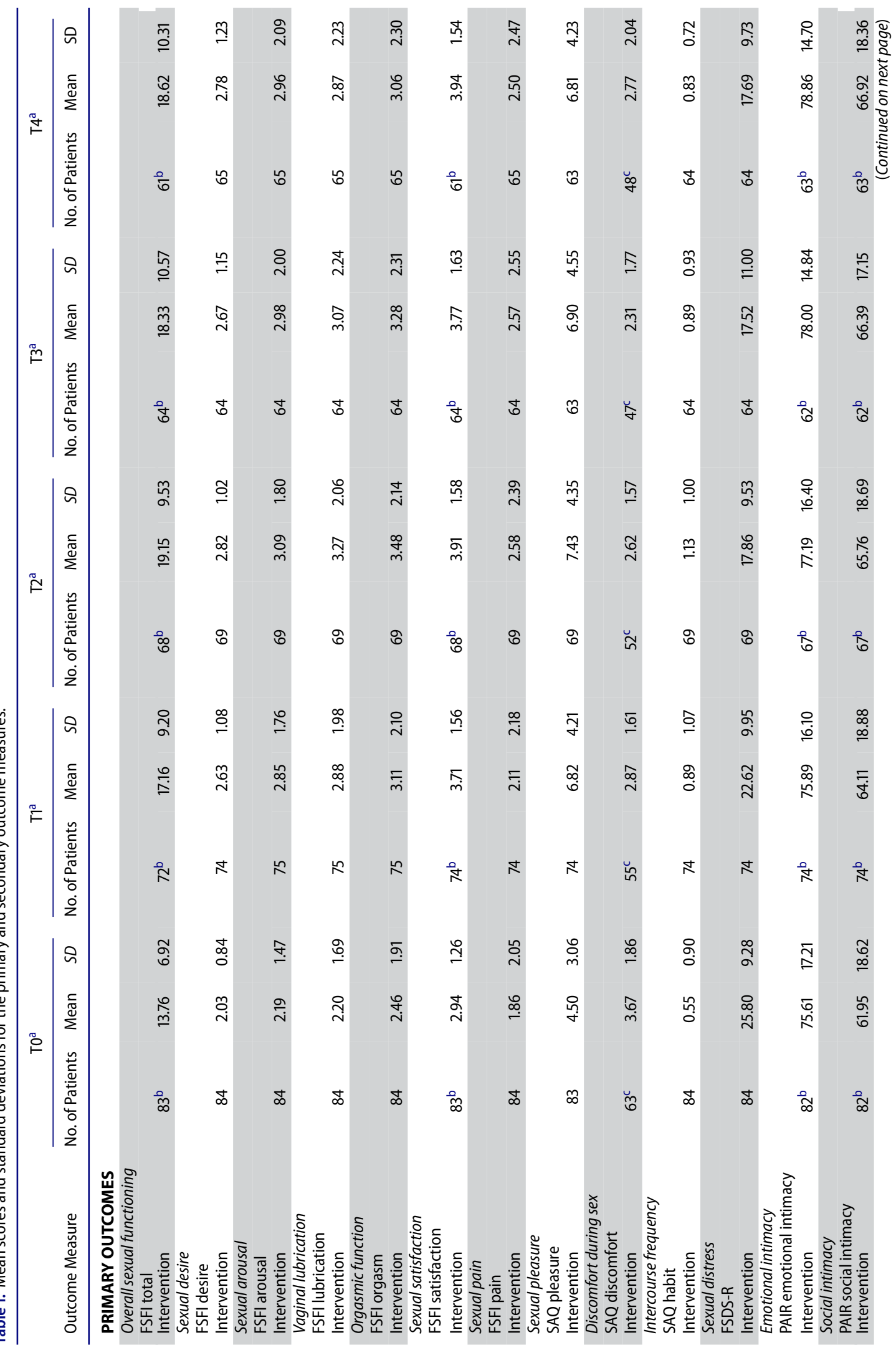




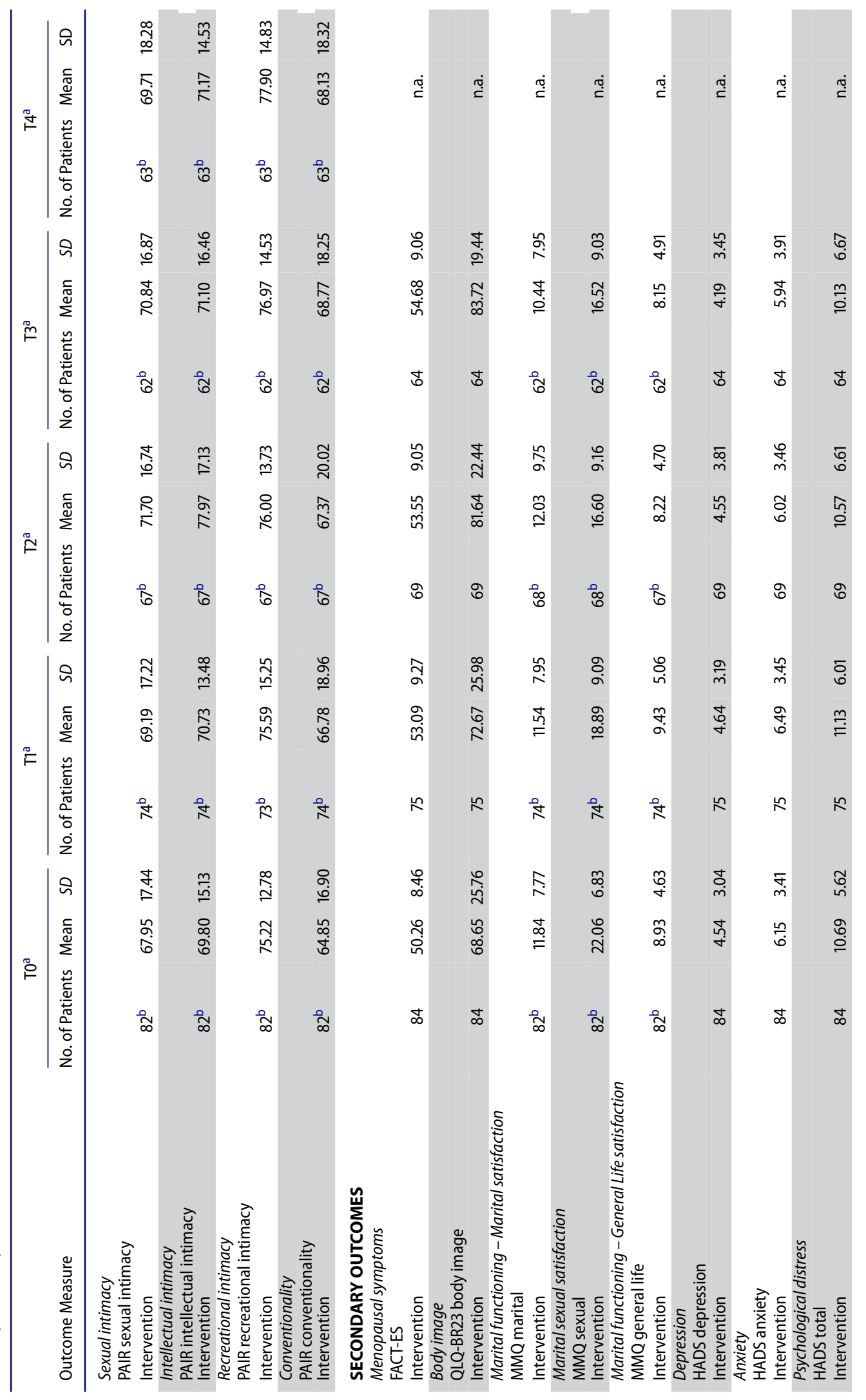




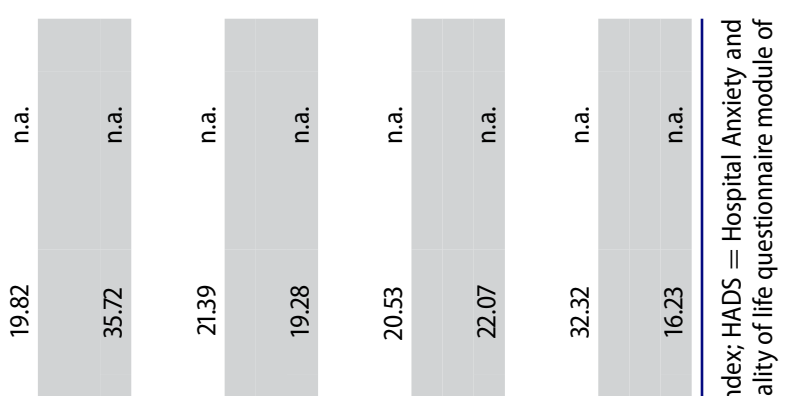

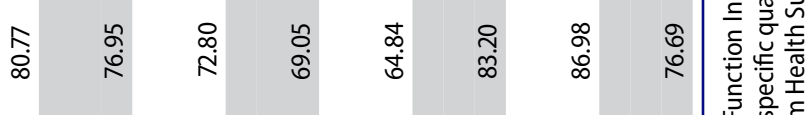

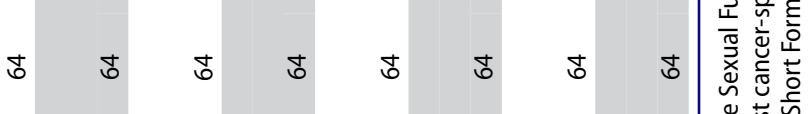

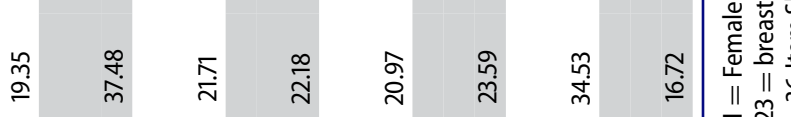

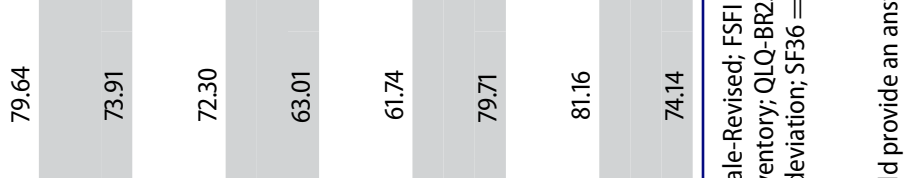

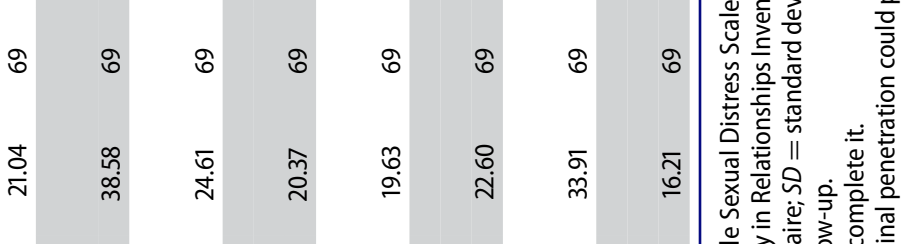

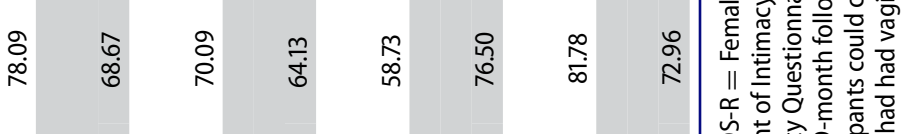

$\kappa n n k n \kappa n$

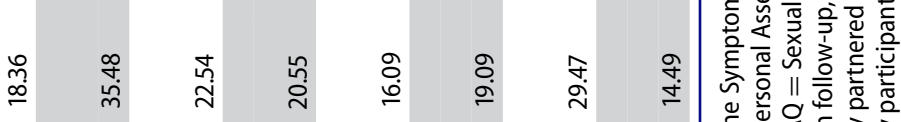

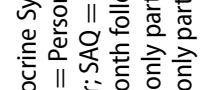

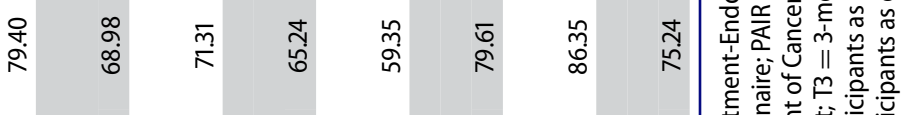

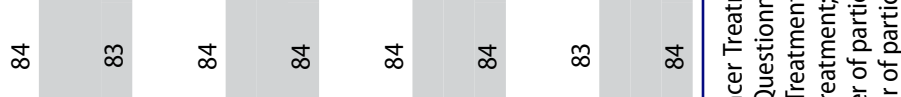

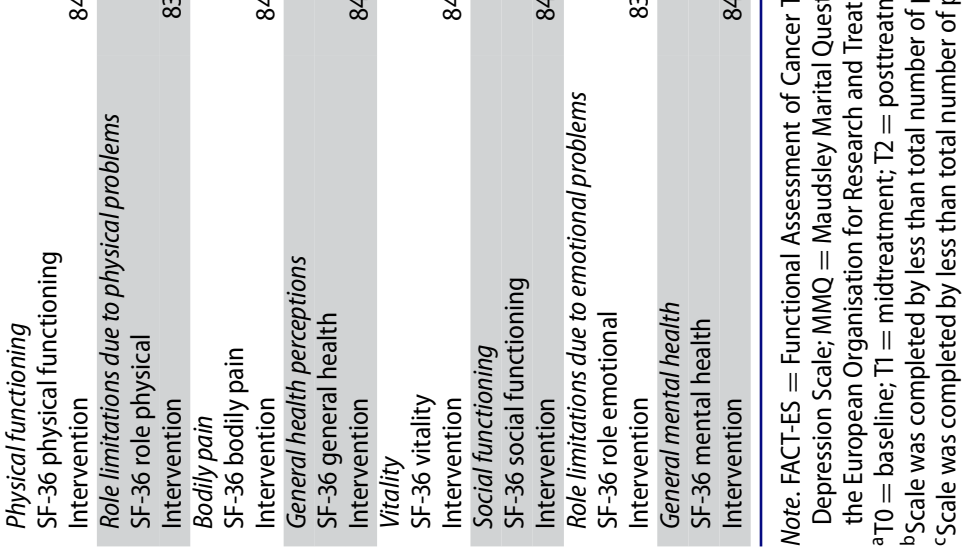


Table 2. Statistically significant linear and quadratic effects of time for the primary and secondary outcomes.

\begin{tabular}{|c|c|c|c|c|c|c|c|c|c|c|c|c|c|}
\hline \multirow[b]{2}{*}{ Outcome Measure } & \multicolumn{5}{|c|}{ Linear and Quadratic Growth Model } & \multicolumn{4}{|c|}{$\mathrm{P} 1^{\mathrm{a}}$} & \multicolumn{4}{|c|}{$\mathrm{P} 2^{\mathrm{a}}$} \\
\hline & & Coefficient & $S E$ & $p$ & $\mathrm{ES}^{\mathrm{b}}$ & Coefficient & $S E$ & $p$ & $\mathrm{ES}^{\mathrm{b}}$ & Coefficient & SE & $p$ & $\mathrm{ES}^{\mathrm{b}}$ \\
\hline \multicolumn{14}{|l|}{ PRIMARY OUTCOMES } \\
\hline \multirow{3}{*}{$\begin{array}{l}\text { Overall sexual functioning } \\
\text { FSFI total }\end{array}$} & & & & & & & & & & & & & \\
\hline & Linear & 3.70 & 0.77 & $<.001$ & & 2.33 & 0.61 & .000 & 0.45 & -0.77 & 0.65 & .238 & -0.14 \\
\hline & Quadratic & -0.75 & 0.18 & $<.001$ & & & & & & & & & \\
\hline \multicolumn{14}{|l|}{ Sexual desire } \\
\hline \multirow[t]{2}{*}{ FSFI desire } & Linear & 0.54 & 0.09 & $<.001$ & & 0.36 & 0.07 & .000 & 0.57 & -0.09 & 0.07 & .246 & -0.13 \\
\hline & Quadratic & -0.10 & 0.02 & $<.001$ & & & & & & & & & \\
\hline \multicolumn{14}{|l|}{ Sexual arousal } \\
\hline FSFI arousal & $\begin{array}{l}\text { Linear } \\
\text { Quadratic }\end{array}$ & $\begin{array}{r}0.66 \\
-0.13\end{array}$ & $\begin{array}{l}0.16 \\
0.04\end{array}$ & $\begin{array}{r}<.001 \\
.001\end{array}$ & & 0.41 & 0.12 & .001 & 0.39 & -0.13 & 0.13 & .302 & -0.12 \\
\hline \multicolumn{14}{|l|}{ Vaginal lubrication } \\
\hline FSFI lubrication & $\begin{array}{l}\text { Linear } \\
\text { Quadratic }\end{array}$ & $\begin{array}{r}0.79 \\
-0.17\end{array}$ & $\begin{array}{l}0.17 \\
0.04\end{array}$ & $\begin{array}{l}<.001 \\
<.001\end{array}$ & & 0.48 & 0.13 & .000 & 0.42 & -0.26 & 0.14 & .069 & -0.21 \\
\hline \multicolumn{14}{|l|}{ Orgasmic function } \\
\hline \multirow[t]{2}{*}{ FSFI orgasm } & Linear & 0.77 & 0.20 & $<.001$ & & 0.47 & 0.15 & .001 & 0.35 & -0.25 & 0.15 & .105 & -0.18 \\
\hline & Quadratic & -0.16 & 0.05 & .001 & & & & & & & & & \\
\hline Sexual satisfaction & & & & & & & & & & & & & \\
\hline FSFI satisfaction & Linear & 0.66 & 0.14 & $<.001$ & & 0.43 & 0.10 & .000 & 0.47 & -0.08 & 0.11 & .455 & -0.08 \\
\hline & Quadratic & -0.12 & 0.03 & $<.001$ & & & & & & & & & \\
\hline Sexual pain & & & & & & & & & & & & & \\
\hline FSFI pain & Linear & 0.42 & 0.20 & .034 & 0.27 & & & & & & & & \\
\hline & Quadratic & -0.07 & 0.05 & 118 & & & & & & & & & \\
\hline Sexual pleasure & & & & & & & & & & & & & \\
\hline SAQ pleasure & Linear & 2.24 & 0.38 & $<.001$ & & 1.36 & 0.28 & .000 & 0.56 & -0.59 & 0.29 & .044 & -0.23 \\
\hline & Quadratic & -0.47 & 0.09 & $<.001$ & & & & & & & & & \\
\hline Discomfort during intercours & & & & & & & & & & & & & \\
\hline SAQ discomfort & Linear & -1.07 & 0.16 & $<.001$ & & -0.59 & 0.14 & .000 & -0.57 & 0.17 & 0.15 & .264 & 0.15 \\
\hline & Quadratic & 0.21 & 0.04 & $<.001$ & & & & & & & & & \\
\hline Intercourse frequency & & & & & & & & & & & & & \\
\hline SAQ habit & Linear & 0.44 & 0.11 & $<.001$ & & 0.28 & 0.07 & .000 & 0.43 & -0.17 & 0.07 & .028 & -0.24 \\
\hline & Quadratic & -0.10 & 0.03 & $<.001$ & & & & & & & & & \\
\hline Sexual distress & & & & & & & & & & & & & \\
\hline FSDS-R & Linear & -5.39 & 0.75 & $<.001$ & & -3.90 & 0.66 & .000 & -0.72 & -0.02 & 0.70 & .977 & 0.00 \\
\hline & Quadratic & 0.85 & 0.17 & $<.001$ & & & & & & & & & \\
\hline Social intimacy & & & & & & & & & & & & & \\
\hline PAIR social & Linear & 2.24 & 1.03 & .031 & 0.28 & & & & & & & & \\
\hline & Quadratic & -0.32 & 0.25 & .200 & & & & & & & & & \\
\hline Sexual intimacy & & & & & & & & & & & & & \\
\hline PAIR sexual & Linear & 2.90 & 1.33 & .031 & & 1.61 & 1.18 & 172 & 0.16 & -1.30 & 1.25 & .299 & -0.12 \\
\hline & Quadratic & -0.66 & 0.32 & .040 & & & & & & & & & \\
\hline Intellectual intimacy & & & & & & & & & & & & & \\
\hline PAIR intellectual & Linear & 4.66 & 1.37 & .001 & & 3.34 & 1.07 & .002 & 0.36 & -3.33 & 1.13 & .003 & -0.34 \\
\hline & Quadratic & -1.14 & 0.33 & .001 & & & & & & & & & \\
\hline SECONDARY OUTCOME & & & & & & & & & & & & & \\
\hline Menopausal symptoms & & & & & & & & & & & & & \\
\hline FACT-ES & Linear & 2.65 & 0.82 & .001 & 0.48 & & & & & & & & \\
\hline & Quadratic & -0.43 & 0.26 & .097 & & & & & & & & & \\
\hline Body image & & & & & & & & & & & & & \\
\hline QLQ-BR23 body image & Linear & 7.52 & 2.49 & .003 & 0.46 & & & & & & & & \\
\hline & Quadratic & -0.81 & 0.80 & .318 & & & & & & & & & \\
\hline Marital sexual satisfaction & & & & & & & & & & & & & \\
\hline MMQ sexual & Linear & -3.98 & 1.00 & $<.001$ & & & & & -0.69 & & & & 0.01 \\
\hline & Quadratic & 0.77 & 0.33 & .019 & & & & & & & & & \\
\hline General health perceptions & & & & & & & & & & & & & \\
\hline SF-36 general health & Linear & -4.15 & 2.09 & .048 & & & & & -0.10 & & & & 0.29 \\
\hline & Quadratic & 1.71 & 0.68 & .013 & & & & & & & & & \\
\hline
\end{tabular}

Note. Bold font indicates a significant effect of time and time coefficients for P1 or P2 that are significantly different from zero. $\mathrm{ES}=$ effect size; FACT-ES = Functional Assessment of Cancer Treatment-Endocrine Symptoms; FSDS-R = Female Sexual Distress ScaleRevised; FSFI = Female Sexual Function Index; MMQ = Maudsley Marital Questionnaire; PAIR = Personal Assessment of Intimacy in Relationships Inventory; QLQ-BR23 = breast cancer-specific quality of life questionnaire module of the European Organisation for Research and Treatment of Cancer; SAQ = Sexual Activity Questionnaire; SE = standard error; SF36 = 36-Item Short Form Health Survey.

a 1 1 = active treatment phase; $\mathrm{P} 2$ = follow-up phase.

${ }^{b}$ The effect size for all primary outcomes and for the secondary outcomes with only a significant linear effect of time was calculated based on the $t$-test statistic: $(2 * t) /(\sqrt{ } d f)$. For the secondary outcomes with a significant quadratic effect of time, the effect size was

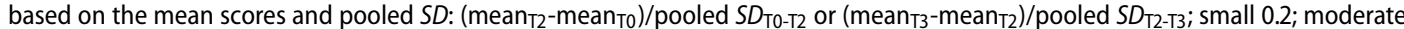
0.5 , large 0.8 . 
perceived therapy burden (one woman), lack of motivation (one woman), and physical problems interfering with the use of a computer (one woman). Two women did not provide a reason.

\section{Primary Outcomes}

For each primary outcome, the model including both a linear and a quadratic effect of time showed the best fit based on the AIC and BIC. We fitted the piecewise growth model for the outcomes that had a statistically significant quadratic effect of time (see Table 2). Maintenance of the treatment effect during the nine-month follow-up (P2) was observed for overall sexual functioning (FSFI total score: $\mathrm{p}_{\mathrm{P} 2}=.238$ ), sexual desire (FSFI desire subscale: $\mathrm{p}_{\mathrm{P} 2}=.246$ ), sexual arousal (FSFI arousal subscale: $\mathrm{p}_{\mathrm{P} 2}=.302$ ), vaginal lubrication (FSFI lubrication subscale: $\mathrm{p}_{\mathrm{P} 2}=.069$ ), orgasmic function (FSFI orgasm subscale: $\mathrm{p}_{\mathrm{P} 2}=.105$ ), sexual satisfaction (FSFI satisfaction subscale: $\mathrm{p}_{\mathrm{P} 2}=.455$ ), discomfort during intercourse (SAQ discomfort subscale: $\left.\mathrm{p}_{\mathrm{P} 2}=.264\right)$, and sexual distress (FSDS-R: $\mathrm{p}_{\mathrm{P} 2}=.977$ ). Tables 1 and 2 display the mean scores and effect sizes.

We observed a statistically significant decrease during P2 for sexual pleasure (SAQ pleasure subscale: $\left.\mathrm{p}_{\mathrm{P} 2}=.044\right)$, intercourse frequency (SAQ habit subscale: $\mathrm{p}_{\mathrm{P} 2}=.028$ ), and intellectual intimacy (PAIR intellectual subscale: $\left.\mathrm{p}_{\mathrm{P} 2}=.003\right)$. We would note that although there was a decrease in sexual pleasure and intercourse frequency during the follow-up period, the follow-up scores did not return to baseline levels (see mean scores and effect sizes in Tables 1 and 2). Intellectual intimacy scores did return to the baseline level. Although we found both a linear and quadratic effect of time for sexual intimacy (PAIR sexual subscale, see Table 2), no significant changes were detected within P2.

We observed a statistically significant linear effect of time, but not a quadratic effect, for sexual pain (FSFI pain subscale: $\mathrm{p}_{\text {linearT0-T4 }}=.034$ ) and social intimacy (PAIR social subscale: plinearT0-T4 $_{1}=.031$ ). This indicates that there was a continuous decrease in sexual pain and an increase in social intimacy from T0 to T4. There were no statistically significant changes over time observed for the PAIR subscales emotional intimacy, recreational intimacy, or conventionality.

\section{Secondary Outcomes}

The secondary outcomes were assessed from T0 to T3. For each outcome, the model including both a linear and quadratic effect of time showed the best fit based on the AIC and BIC. We observed a statistically significant linear effect of time, but not a quadratic effect, for menopausal symptoms (FACT-ES: $\left.\mathrm{p}_{\text {linearT0-T3 }}=.001\right)$ and body image (QLQ-BR23 body image subscale: $\left.\mathrm{p}_{\text {linearT0-T3 }}=.003\right)$. This indicates that there was a continuous improvement in both outcomes from T0 to T3 (see Tables 1 and 2).

We observed a significant linear and quadratic effect of time for marital sexual satisfaction (MMQ sexual subscale: $\mathrm{p}_{\text {quadraticT0-T3 }}=.019$ ) and general health (SF-36 general health subscale: $\mathrm{p}_{\text {quadraticT0-T3 }}=$ .013). The mean scores and effect sizes (see Tables 1 and 2) show that the improvement in marital sexual satisfaction was maintained during P2. Women's general health improved during P2.

There were no statistically significant changes over time in marital satisfaction or marital general life satisfaction (MMQ marital and general life subscales), psychological distress (HADS total, depression and anxiety scales), or the other health-related quality of life domains (SF-36 subscales).

\section{Discussion}

These results indicate that the positive effects of Internet-based CBT on overall sexual functioning, sexual desire, sexual arousal, vaginal lubrication, discomfort during sex, sexual distress, and body image of BC survivors with a DSM-IV-TR diagnosis of sexual dysfunction observed at the end of CBT (Hummel et al., 2017) were maintained during the three- and nine-month follow-up periods. The linear effect from baseline to three-month follow-up for body image indicates that this outcome improved even further after the completion of the CBT. Sexual pleasure was the only domain that, after an improvement during the Internet-based CBT, decreased significantly in the follow-up period. It did not, however, return to 
baseline levels. This SAQ subscale includes items covering a wide variety of topics, such as enjoying sex, desiring to have sex, feeling satisfied after sex, and the frequency of intercourse. It may be that, after completion of the CBT, the loss of therapist encouragement to engage in sex may have resulted in some loss of effect in these areas. This was also reflected in the modest, although not statistically significant, decrease in the other sexual function measures. The fact that we observed a quadratic effect of time for sexual intimacy, but no significant changes within either P1 or P2 may be due to the fact that the changes in scores for this variable from T0 to T4, although significant, were relatively small and were no longer significant when analyzing the two time periods separately.

In the current analysis, we observed maintenance of the treatment effect in orgasmic function, sexual satisfaction, sexual pain, menopausal symptoms, sexual relationship satisfaction, and social intimacy. We would note that, based on our original between-group analysis of the short-term effects of the CBT program (Hummel et al., 2017), improvements from the baseline to T2 assessment in these outcomes were also observed in the waiting-list control group or were only marginally significantly better in the CBT group. This was also the case for intercourse frequency and intellectual intimacy. Nevertheless, the current results demonstrate that, except for a slight decrease in intercourse frequency (although not to baseline levels) and a decrease in intellectual intimacy, these outcomes remained stable in the period after completion of the Internet-based CBT.

Women reported an improvement in general health perceptions three months post-CBT. It might be that after completing the Internet-based CBT women started reflecting on the changes that they had experienced in their sexual functioning and consequently evaluated their general health more positively.

Relationship intimacy, marital functioning, psychological distress, and health-related quality of life did not change significantly during CBT (Hummel et al., 2017) or, as shown in the current analysis, after completion of the CBT. This probably reflects the fact that there was relatively little room for improvement in these areas, as women who had serious relationship problems or psychological comorbidity were excluded from study participation.

Both the pre- and post-CBT FSFI scores of our study sample were lower (indicating a lower level of sexual functioning) than those reported by women from the general population treated with Internetbased CBT for sexual problems (Jones \& McCabe, 2011). In large part, this may reflect the fact that the women in our study had a sexual dysfunction according to DSM-IV-TR criteria, whereas those in the trial of Jones and McCabe (2011) were selected on the basis of self-reported sexual problems only. It could also be that BC survivors who seek sex therapy have more severe sexual problems than women from the general population (Ter Kuile et al., 2006) who seek professional help.

The current study had several limitations that should be noted. First, we could not compare the longerterm sexual functioning of the intervention group with that of the waiting-list control group. As noted earlier, women in the control group were offered the opportunity to undergo the Internet-based CBT after completion of the T2 questionnaire. This was done because both we and the institutional review board did not consider it to be ethically acceptable to withhold therapy from the women in the control group, all of whom had a sexual dysfunction according to DSM-IV-TR criteria, for an extended period of time. However, as the control group had only minor changes on the outcome measures in the 23 weeks between baseline and the T2 assessment (Hummel et al., 2017), we think that a sudden improvement in the follow-up period would have been unlikely.

Second, in order to reduce respondent burden and increase response rates, we did not assess the secondary outcomes at the nine-month post-CBT point. This necessitated use of different statistical methods for the analysis of the primary and secondary outcomes.

Third, there was some loss to follow-up during the course of our study $(10.7 \%, 17.9 \%, 23.8 \%$, and $22.6 \%$ at $\mathrm{T} 1$ through $\mathrm{T} 4$, respectively). This is not uncommon in such intervention trials (Eysenbach, 2005). We dealt with the issue of missing data by using appropriate mixed-effects models (Peters et al., 2012).

Our study also had a number of strengths, including the availability of several post-intervention follow-up assessments, the use of a range of relevant, validated outcomes measures, and the inclusion of women from both academic and community hospitals. 
Our results indicate that the positive effects of Internet-based CBT on most sexual functioning domains, sexual distress, and body image of BC survivors with a sexual dysfunction according to DSM$I V$-TR criteria are maintained well beyond the immediate post-CBT period. The availability of clinically effective, Internet-based sex therapy for breast cancer survivors will hopefully increase the likelihood that women who otherwise might not seek professional help for their sexual problems due to practical or social reasons (e.g., reluctance to discuss sexual issues in face-to-face settings) will do so.

\section{Acknowledgments}

Virenze Institute of Mental Health Care collaborated on the development of the Internet-based cognitive behavioral therapy program and Internet platform, employed the sexologists, and provided the platform to the participants, with funding from The Netherlands Cancer Institute. We would like to thank Hannah Lassche and Aukje Schade for their work and dedication as therapists (along with Eva Broomans and Daniela Hahn). We also thank the patients and their partners for their willingness to participate in the study.

\section{Funding}

This study was supported financially by the Dutch Cancer Society (grant number NKI 2012-5388), the Dutch Pink Ribbon Foundation (grant number 2012.WO21.C138), and The Netherlands Cancer Institute

\section{References}

Aaronson, N. K., Muller, M., Cohen, P. D., Essink-Bot, M. L., Fekkes, M., Sanderman, R., ... Verrips, E. (1998). Translation, validation, and norming of the Dutch language version of the SF-36 Health Survey in community and chronic disease populations. Journal of Clinical Epidemiology, 51(11), 1055-1068. doi:10.1016/S0895-4356(98)00097-3.

Akaike, H. (1998). Information theory and an extension of the maximum likelihood principle. In E. Parzen, K. Tanabe, \& G. Kitagawa (Eds.), Selected papers of Hirotugu Akaike (pp. 199-213). New York, NY: Springer.

American Psychiatric Association. (2000). Diagnostic and statistical manual of mental disorders (4th ed., text rev.). Washington, DC: Author.

Arrindell, W. A., Boelens, W., \& Lambert, H. (1983). On the psychometric properties of the Maudsley Marital Questionnaire (MMQ): Evaluation of self-ratings in distressed and 'normal' volunteer couples based on the Dutch version. Personality and Individual Differences, 4(3), 293-306. doi:10.1016/0191-8869(83)90151-4.

Atkins, L., \& Fallowfield, L. J. (2007). Fallowfield's Sexual Activity Questionnaire in women with without and at risk of cancer. Menopause International, 13(3), 103-109. doi:10.1258/175404507781605578

Bjelland, I., Dahl, A. A., Haug, T. T., \& Neckelmann, D. (2002). The validity of the Hospital Anxiety and Depression Scale: An updated literature review. Journal of Psychosomatic Research, 52(2), 69-77. doi:10.1016/S0022-3999(01)00296-3.

Bollen, K., \& Curran, P. (2006). Latent curve models. Hoboken, NJ: Wiley.

Brotto, L., Atallah, S., Johnson-Agbakwu, C., Rosenbaum, T., Abdo, C., Byers, E. S., ... Wylie, K. (2016). Psychological and interpersonal dimensions of sexual function and dysfunction. The Journal of Sexual Medicine, 13(4), 538-571. doi:10.1016/j.jsxm.2016.01.019.

Cohen, J. (1988). Statistical power analysis for the behavioral sciences (2nd ed.). Hillsdale, NJ: Erlbaum.

Derogatis, L., Clayton, A., Lewis-D’Agostino, D., Wunderlich, G., \& Fu, Y. (2008). Validation of the Female Sexual Distress Scale-Revised for assessing distress in women with hypoactive sexual desire disorder. The Journal of Sexual Medicine, 5(2), 357-364. doi:10.1111/j.1743-6109.2007.00672.x.

Derogatis, L. R., Rosen, R., Leiblum, S., Burnett, A., \& Heiman, J. (2002). The Female Sexual Distress Scale (FSDS): Initial validation of a standardized scale for assessment of sexually related personal distress in women. Journal of Sex \& Marital Therapy, 28(4), 317-330. doi:10.1080/00926230290001448.

Eysenbach, G. (2005). The law of attrition. Journal of Medical Internet Research, 7(1), e11. doi:10.2196/jmir.7.1.e11.

Fallowfield, L. J., Leaity, S. K., Howell, A., Benson, S., \& Cella, D. (1999). Assessment of quality of life in women undergoing hormonal therapy for breast cancer: Validation of an endocrine symptom subscale for the FACT-B. Breast Cancer Research and Treatment, 55(2), 189-199. doi:10.1023/A:1006263818115.

Hernández-Lloreda M. V., Colmenares F., \& Martínez-Arias R. (2004). Application of piecewise hierarchical linear growth modeling to the study of continuity in behavioral development of baboons (Papio hamadryas). Journal of Comparative Psychology, 118(3), 316-324. doi:10.1037/0735-7036.118.3.316.

Hucker, A., \& McCabe, M. P. (2014). An online, mindfulness-based, cognitive-behavioral therapy for female sexual difficulties: Impact on relationship functioning. Journal of Sex \& Marital Therapy, 40(6), 561-576. doi:10.1080/0092623X.2013.796578. 
Hummel, S. B., Lankveld, J. J. D. M. v., Oldenburg, H. S. A., Hahn, D. E. E., Kieffer, J. M., Gerritsma, M. A., ... Aaronson, N. K. (2017). Efficacy of Internet-based cognitive behavioral therapy in improving sexual functioning of breast cancer survivors: Results of a randomized controlled trial. Journal of Clinical Oncology, 35(12), 1328-1340. doi:10.1200/JCO.2016.69.6021.

Jones, L. M., \& McCabe, M. P. (2011). The effectiveness of an Internet-based psychological treatment program for female sexual dysfunction. The Journal of Sexual Medicine, 8(10), 2781-2792. doi:10.1111/j.1743-6109.2011.02381.x.

Kedde, H., van de Wiel, H. B., Weijmar Schultz, W. C., \& Wijsen, C. (2013). Sexual dysfunction in young women with breast cancer. Support Care Cancer, 21(1), 271-280. doi:10.1007/s00520-012-1521-9.

Peters, S. A., Bots, M. L., den Ruijter, H. M., Palmer, M. K., Grobbee, D. E., Crouse, J. R., 3rd, ... Koffijberg, H. (2012). Multiple imputation of missing repeated outcome measurements did not add to linear mixed-effects models. Journal of Clinical Epidemiology, 65(6), 686-695. doi:10.1016/j.jclinepi.2011.11.012.

Raggio, G. A., Butryn, M. L., Arigo, D., Mikorski, R., \& Palmer, S. C. (2014). Prevalence and correlates of sexual morbidity in long-term breast cancer survivors. Psychology \& Health, 29(6), 632-650. doi:10.1080/08870446.2013.879136.

Rosen, R., Brown, C., Heiman, J., Leiblum, S., Meston, C., Shabsigh, R., ... D’Agostino, R., Jr. (2000). The Female Sexual Function Index (FSFI): A multidimensional self-report instrument for the assessment of female sexual function. Journal of Sex \& Marital Therapy, 26(2), 191-208. doi:10.1080/009262300278597.

Sadovsky, R., Basson, R., Krychman, M., Morales, A. M., Schover, L., Wang, R., \& Incrocci, L. (2010). Cancer and sexual problems. The Journal of Sexual Medicine, 7(1, pt. 2), 349-373. doi:10.1111/j.1743-6109.2009.01620.x.

Schaefer, M. T., \& Olson, D. H. (1981). Assessing intimacy: The Pair Inventory. Journal of Marital and Family Therapy, 7(1), 47-60. doi:10.1111/j.1752-0606.1981.tb01351.x.

Schover, L. R., Yuan, Y., Fellman, B. M., Odensky, E., Lewis, P. E., \& Martinetti, P. (2013). Efficacy trial of an Internet-based intervention for cancer-related female sexual dysfunction. Journal of the National Comprehensive Cancer Network, 11(11), 1389-1397. doi:10.6004/jnccn.2013.0162.

Schwarz, G. (1978). Estimating the dimension of a model. The Annals of Statistics, 6(2), 461-464. doi:10.1214/aos/1176344136.

Sprangers, M. A., Groenvold, M., Arraras, J. I., Franklin, J., te Velde, A., Muller, M., ... Aaronson, N. K. (1996). The European organization for research and treatment of cancer breast cancer-specific quality-of-life questionnaire module: First results from a three-country field study. Journal of Clinical Oncology, 14(10), 2756-2768. doi:10.1200/JCO.1996.14.10.2756.

Ter Kuile, M. M., Both, S., \& van Lankveld, J. J. (2010). Cognitive behavioral therapy for sexual dysfunctions in women. Psychiatric Clinics of North America, 33(3), 595-610. doi:10.1016/j.psc.2010.04.010.

Ter Kuile, M. M., Brauer, M., \& Laan, E. (2006). The Female Sexual Function Index (FSFI) and the Female Sexual Distress Scale (FSDS): Psychometric properties within a Dutch population. Journal of Sex \& Marital Therapy, 32(4), $289-304$. doi:10.1080/00926230600666261.

Thirlaway, K., Fallowfield, L., \& Cuzick, J. (1996). The Sexual Activity Questionnaire: A measure of women's sexual functioning. Quality of Life Research, 5(1), 81-90. doi:10.1007/BF00435972.

Van Lankveld, J. J., Leusink, P., Van Diest, S., Gijs, L., \& Slob, A. K. (2009). Internet-based brief sex therapy for heterosexual men with sexual dysfunctions: A randomized controlled pilot trial. The Journal of Sexual Medicine, 6(8), $2224-2236$. doi:10.1111/j.1743-6109.2009.01321.x.

Ware, J., \& Sherbourne, C. (1992). The MOS 36-item short-form health survey (SF-36) I. Conceptual framework and item selection. Medical Care, 30(6), 473-483. doi:10.1097/00005650-199206000-00002.

Zigmond, A. S., \& Snaith, R. P. (1983). The Hospital Anxiety and Depression Scale. Acta Psychiatrica Scandinavica, 67(6), 361-370. doi:10.1111/j.1600-0447.1983.tb09716.x. 